ORIGINAL ARTICLE

\title{
Levels of apolipoproteins as risk factors for coronary artery disease
}

\author{
Níveis de apolipoproteínas como fatores de risco para doença arterial coronariana
}

Mohmed Ashmaig', Khalifa Ashmeik², Atif Ahmed², Samia Sobki³, Muheeb Abdulla²

\begin{abstract}
Introduction: The Saudi population is renowned for their unhealthy diet and physical inactivity.

Objective: To investigate apolipoproteins B (apo B), A-I (apo A-I) and B/A-I as risk factors that might be associated with increased incidence of the coronary artery disease.

Methods: Two hundred and twenty subjects suspected of having the coronary artery disease underwent coronary angiography and blood draw following a 12-hour fast. Apolipoproteins B and A-I were both measured by turbidimetric methods.

Results: One hundred and forty subjects were positive and 80 subjects were negative for the coronary artery disease. Both apolipoproteins were found to be statistically significant as risk factors for the coronary artery disease: apolipoprotein B (105.33 \pm 29.22 versus $94.56 \pm 24.35 \mathrm{mg} / \mathrm{dL}, \mathrm{p}<0.003)$, apolipoprotein $A-I(123.98 \pm 25.6$ versus $133.5 \pm 24.1 \mathrm{mg} / \mathrm{dL}, \mathrm{p}<0.004)$ and apolipoproteins B/A-I $(0.88 \pm 0.28$ versus $0.72 \pm 0.2, p<0.0001)$.

Conclusions: Measurements of apolipoproteins B, A-I and calculation of apolipoproteins B/A-I ratio either instead of or in addition to the customary measurements of lipoprotein cholesterol may significantly add to predicting and assessing the coronary risk factors in the Saudi population.
\end{abstract}

Keywords: apolipoprotein B; apolipoprotein A-l; coronary artery disease.

\section{Resumo}

Introdução: A população da Arábia Saudita é conhecida por sua dieta não-saudável e inatividade física.

Objetivo: Investigar as apolipoproteínas B (apo B), Al (apo Al) e B/Al como fatores de risco que podem estar associados ao aumento da incidência da doença arterial coronariana.

Métodos: Duzentos e vinte pacientes com suspeita de doença arterial coronariana foram submetidos à angiografia coronária e extração de sangue após jejum de 12 horas. As apolipoproteínas B e Al foram medidas por métodos turbidímetros.

Resultados: Cento e quarenta pacientes foram positivos e 80 foram negativos para a doença arterial coronariana. Ambas apolipoproteínas foram estatisticamente significativas como fatores de risco para doença arterial coronariana: apolipoproteínas B (105,33 $\pm 29,22$ versus 94,56 24,35 mg/dL, $p<0,003), \operatorname{Al}(123,98 \pm 25,6$ versus $133,5 \pm 24,1, p<0,004)$ e $B / A-I(0,88 \pm 0,28$ versus $0,72 \pm 0,2, p<0,0001)$.

Conclusões: As medidas das apolipoproteínas B, Al e o cálculo da relação B/Al tanto por ou em adição às medidas habituais de colesterol das lipoproteínas podem aumentar significativamente a previsão e avaliação dos fatores de risco coronariano na população saudita.

Palavras-chave: apolipoproteína B; apolipoproteína A-l; doença da artéria coronariana.

\section{Introduction}

Total, high density lipoproteins (HDL) and low density lipoproteins (LDL) cholesterol measurements have been used for many years to assess the cardiovascular disease (CVD) risk and to guide preventive therapy ${ }^{1}$. Measurement of atherogenic and nonatherogenic lipoprotein particles in terms of their cholesterol content rather than their particles numbers or size, have been used in most of the early studies in addition to patient management by physicians and in patients' education. Cholesterol was known and assays were available, so at the time it seemed rational to determine lipoproteins in terms of their cholesterol content.

In the mid 1940s, the lipoprotein major classes and subclasses were recognized and characterized. As awareness of the lipoproteins increased, apolipoprotein B (apo B)

\footnotetext{
1 Scientist at Berkeley Heart Lab. Inc, California, USA.

${ }^{2}$ Cardiologists at the Prince Sultan Cardiac Center, Riyadh Military Hospital, Saudi Arabia.

${ }^{3}$ Pathologist at the Department of Pathology, Riyadh Military Hospital, Saudi Arabia.

Financial support: none.

Conflict of interest: nothing to declare.

Submitted on: 06.10.10. Accepted on: 09.02.11.

J Vasc Bras. 2011;10(4):293-297.
} 
was recognized to be present as one molecule per each LDL particle, and apo A-I was shown to be present in about $70 \%$ of HDL particles ${ }^{2,3}$.

Subsequently, as immunoassays for the apolipoproteins became available, evidence has accumulated that the protein constituents are a better metric for assessing the risk associated with the lipoproteins, especially so for $\mathrm{LDL}^{4-6}$.

Apo B and apo A-I are important components of nonHDL and HDL lipoprotein particles, respectively, and there is a wealth of evidence supporting their measurements to improve the prediction of CVD risk ${ }^{7-10}$.

Consistently, accumulating evidence has yielded that the risk of coronary atherosclerotic cardiovascular disease is directly related to plasma lipid, lipoprotein, and apolipoprotein concentrations in Western populations, but the relationships between the serum apo A-I and apo B levels and coronary artery disease (CAD) have not been studied in the Saudi population.

\section{Materials And Methods}

\section{Subjects}

To investigate the possible relationship of the serum levels of apo B and apo A-I with coronary lesions and number of vessels diseased, ethical approval from the local medical ethical committee at Prince Sultan Cardiac Centre in Riyadh, Saudi Arabia, was obtained before the study started. Informed written consent was obtained from all subjects before blood draw. Two hundred and twenty subjects were randomly selected and recruited from the Cardiology Department at the Prince Sultan Cardiac Center, if they were suspected of having CAD (not previously diagnosed as $\mathrm{CAD}$ patient) and were not on lipid lowering or any other medications, except for diabetes control medicine and if they were falling into the inclusion criteria.

The subjects were then divided into two groups depending on the findings of the coronary angiogram: positive for $\mathrm{CAD}(\mathrm{CAD}+)$, if an occlusion of $\geq 50 \%$ present in any coronary artery was detected; negative for CAD (CAD-), if no occlusion was detected by coronary angiography.

Information on other medical conditions were collected, such as: hypertension (classified as blood pressure $>120 / 80 \mathrm{mmHg}$ ), diabetes mellitus (types I or II), metabolic syndrome (classified by high triglycerides, low HDL, small dense LDL or high non-HDL cholesterol, uncontrolled diabetes as shown by high $\mathrm{HbA1C}$ ), and cigarette smoking by subject's questionnaire (data not shown).

\section{Inclusion criteria}

Subjects were selected for coronary angiography based on one or more of the following criteria: chest pain, shortness of breath, resting or exercise stress electrocardiogram (ECG) changes (such as abnormal Q-waves, isoelectric period - ST segment - depression or ST segment elevation), or hypertension.

\section{Exclusion criteria}

Subjects with long hospitalization or severe or chronic illness, such as cancer or renal disease, were excluded from this study.

\section{Blood collection}

All subjects were fasted for 12 hours, and then venous blood was obtained by venipuncture using a 21-gauge venflon needle just before the angiogram procedure had started. Blood was collected into plain serum separator tube (SST) tubes for apo B and apo A-I measurements. All subjects underwent a standard coronary angiography carried out by a qualified medical cardiologist at the Prince Sultan Cardiac Center, Riyadh, Saudi Arabia.

\section{Apolipoprotein analysis}

Apo B and apo A-I were determined by an automated immunotubridimetric assay, using specific antibody against apo B and apo A-I (on Hitachi 911 auto-analyzer, Roche Diagnostics, Riyadh, Saudi Arabia). The analyzer performance was verified to meet appropriate standards of accuracy and precision, which was confirmed in each analytical run by analysis of two levels of control materials (low and high), all of which met acceptance criteria (data not shown).

\section{Statistical analysis}

Data were analyzed using the following software: JMP from SAS Institute Inc. (Cary, NC, USA); Instat statistical package from Instat Corporation (Instat R, San Diego. The following statistical tests were used: nonparametric analysis of variance (ANOVA), student's unpaired $t$-test, and the $\chi^{2}$ test. All data are presented as mean \pm standard deviation (SD); statistical significance was accepted at $\mathrm{p}<0.05$. 


\section{Results}

The population sampled was comprised of 220 subjects (75\% males and $25 \%$ females), with the characteristics and apolipoprotein results shown in Table 1.

Coronary angiography was used to distinguish between normal and diseased coronary arteries, and for determining the severity of disease. A total of 128 subjects (one subject was excluded due to incomplete data) had between one to five diseased vessels, with disease severity ranging from $>50$ to $100 \%$ occlusion. Of these subjects, $25 \%$ had single vessel disease; $31 \%$, double vessel disease; $34 \%$, triple vessel disease; $9 \%$, four diseased vessels, and $2 \%$, five diseased vessels.

The CAD+ Group was older than the CAD- Group by about ten years on average, $79 \%$ of the CAD+ Group and $55 \%$ of the CAD- Group were male. Hypertension (classified as blood pressure $>120 / 80 \mathrm{mmHg}$ ) was present in $22 \%$ of the CAD+ Group and 34\% in CAD- Group. No subjects had renal disease, known previous coronary heart disease (CHD), known myocardial infarction, lipid lowering medication (nor other medication except for diabetes control), or cerebrovascular disease. A total of $45 \%$ in the CHD positive group (mean $\mathrm{HbAlC}=9.0 \%$ ) and $15 \%$ in the $\mathrm{CHD}$ negative group (mean $\mathrm{HbA1C}=5.9 \%$ ) had diabetes mellitus (types I or II). The metabolic syndrome, which was classified by high triglycerides, low HDL, small dense LDL or high nonHDL cholesterol, uncontrolled diabetes as shown by high $\mathrm{HbA} 1 \mathrm{C}$, was found in $63 \%$ of the $\mathrm{CHD}$ positive compared to only $8 \%$ in the CHD negative group. Cigarette smoking (through subject's questionnaire) was found in 35 and 16\% of the $\mathrm{CAD}+$ and $\mathrm{CAD}$ - groups, respectively.

Apolipoproteins B, A-I and B/A-I were significantly higher in $\mathrm{CAD}+$ than $\mathrm{CAD}-(105.33 \pm 29.22$ versus $94.56 \pm 24.35 \mathrm{mg} / \mathrm{dL}, \mathrm{p}<0.003 ; 123.98 \pm 25.6$ versus $133.5 \pm 24.1 \mathrm{mg} / \mathrm{dL}, \mathrm{p}<0.004$; and $0.88 \pm 0.28$ versus $0.72 \pm 0.2$, $\mathrm{p}<0.0001$ ), respectively. No significant differences were found between subjects with single or multiple (two to five) vessels disease - in other words, the number of diseased vessels was not associated with these levels.

The Odds Ratio for apolipoproteins B/A-I of $>0.72$ was 2.4 (95\% CI=1.32-4.33) when compared with those with apolipoproteins B/A-I of $\leq 0.72(\mathrm{p}<0.006)$.

The Odds Ratio with 95\% CI for apolipoproteins B/A-I was compared with the one calculated from our previous observation (unpublished data) for total cholesterol (T.Chol), non-high density lipoprotein cholesterol (nonHDL-C), LDL cholesterol (LDL-C), triglycerides, small dense LDL, high density lipoprotein cholesterol (HDL-C),
T.Chol/HDL-C (Table 2 and Figure 1). The HDL-C and apolipoproteins B/A-I were found to have the highest Odds Ratios for CAD in Saudi population.

\section{Discussion}

Most current consensus based treatment guidelines still focus primarily on LDL-C for CAD risk assessment and monitoring of therapy. Past studies suggest that several established coronary risk factors of lipid metabolism are strongly associated with CAD. However, more recent evidence suggest that apo B may be a better predictor of risk and better monitor of therapy than LDL-C alone $e^{11-13}$.

Now that immunoassays for the apolipoproteins B and A-I are readily available, these may be implemented in routine practice and may not only improve prediction, but also patient's management ${ }^{2}$. Results from another country

Table 1. Coronary artery disease + and - subject characteristics.

\begin{tabular}{lccc}
\hline Subject characteristics & CAD+ $(\mathrm{n}=140)$ & CAD- $(\mathrm{n}=80)$ & $\mathrm{p}$-value \\
\hline Age group (years) & $51.0 \pm 11.6$ & $41.0 \pm 10.8$ & $<0.0001$ \\
Male/Female (\%) & $79 / 21$ & $35 / 45$ & $<0.0001$ \\
Hypertension (\%) & 22 & 34 & 0.34 \\
Diabetes (\%) & 45 & 15 & $<0.0001$ \\
Smoker (\%) & 35 & 16 & $<0.04$ \\
Apo B mg/dL \pm SD & $105.33 \pm 29.22$ & $94.56 \pm 24.35$ & $<0.003$ \\
Apo Al mg/dL $\pm S D$ & $123.98 \pm 25.6$ & $133.5 \pm 24.1$ & 0.004 \\
Apo B/Apo Al $\pm S D$ & $0.88 \pm 0.28$ & $0.72 \pm 0.2$ & $<0.0001$ \\
\hline
\end{tabular}

CAD: coronary artery disease; SD: standard deviation.

Table 2. Odds Ratios (95\% confidence interval) for the effect of coronary artery disease risk factors on Saudi Population.

\begin{tabular}{lccc}
\hline Lipids/lipoproteins & Odds Ratio & $95 \% \mathrm{Cl}$ & $\mathrm{p}$ \\
\hline Non-HDL-C & 0.7 & $0.4-1.2$ & 0.1 \\
T.Chol. & 0.9 & $0.5-1.7$ & 0.5 \\
LDL-C & 1.4 & $0.8-2.5$ & 0.2 \\
T.Chol/HDL-C & 2.1 & $1.2-3.8$ & $<0.01$ \\
dense LDL & 2.1 & $0.9-4.7$ & 0.06 \\
Triglycerides & 2.2 & $1.3-3.9$ & $<0.005$ \\
Apo B/apo A-l & 2.4 & $1.3-4.3$ & $<0.003$ \\
HDL-C & 2.7 & $1.5-4.7$ & $<0.001$ \\
\hline
\end{tabular}

HDL-C - High density lipoprotein cholesterol; LDL-C - Low density lipoprotein cholesterol; T.Chol - Total cholesterol; LDL - Low density lipoprotein; Apo - Apolipoproteins. Coronary risk factor can be considered a significant risk if the Odds Ratio is greater than 1 and the lower bound of the confidence interval $\geq 1$. The Odds Ratio of the following risk factors: Non-HDL-C, T.Chol, LDL-C, T.Chol/HDL-C, dense LDL, triglycerides and HDL-C were calculated from previous unpublished observations. 


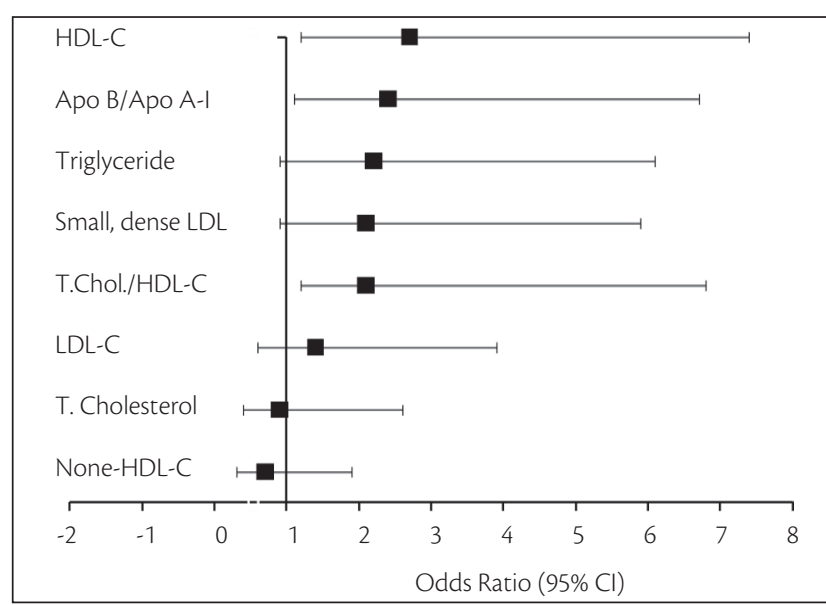

Figure 1. Odds Ratio ( $95 \%$ confidence interval) for coronary artery disease associated with selected risk factors among Saudi Population

geographically nearby indicated that the apoB/apoA-I ratio and $\mathrm{apoB}$ are independent risk factors for $\mathrm{CAD}$ assessment and prediction, and may be superior to any of the lipoprotein cholesterol or lipid ratios ${ }^{14,15}$. Higher total cholesterol, LDL-C, apo B, triglycerides (TG), and lower HDL-C and apo A-I levels were found in patients with $\mathrm{CAD}^{16}$. However, in a previous report, we found that measurements of total cholesterol and LDL-C are insufficient to assess and predict $\mathrm{CAD}$ in the Saudi population.

In this study, we found that apo B, apo A-I and apo B/ apo A-I are strongly associated with CAD with an Odds Ratio for apo B/A-I $>0.72$ of 2.4 (95\%CI 1.32-4.33), when compared to those with apo B/apo A-I of $\leq 0.72$ ( $\mathrm{p}<0.006)$. Furthermore, apo B/A-I values were equivalent in subjects with single or multiple (two to five) vessels disease and this may a beneficial by itself in early predication of CAD. Surprisingly, the small dense LDL measured in the previous study in Saudi population did not have the strongest Odds Ratio as shown in Figure 1. The reason for that may be due to some weakness associated with the method used for small dense LDL measurement, such as overlap between the LDL and HDL boundary. Also, lipoprotein may interfere with small dense LDL measurement particularly in subjects with elevated level of lipoprotein, because they have overlapping density distributions. Since the lipoprotein has larger particle size than all LDL subfractions (including small dense LDL), then the separation of LDL subfractions by gradient gel electrophoresis will be superior to the methods relying on density separation.

The relationship between small, dense LDL and CHD risk has been described in a range of different situation $s^{17-20}$, and HDL sub-fractions are among the new emerging CAD risk factors, and in particular HDL $2 \mathrm{~b}$ has been shown to be linked to cardiovascular risk ${ }^{21}$. The measurement of apo B and total cholesterol or LDL-C does not discriminate between large LDL and small, dense LDL particle size and, in addition, the measurement of apo A-I also does not discriminate between larger cardio-protective HDL and smaller HDL particles. Therefore, the study of LDL and HDL sub-fractions in terms of their particles size in Saudi population is warranted.

\section{Conclusion}

This study suggests that the measurement of apo B, A-I and B/A-I could be routinely used in addition to the lipid profile in order to better assess and discriminate individuals at risk of CAD in the Saudi population.

\section{Acknowledgment}

We would like to thanks Russell Warnick (Health Diagnostic Laboratory, Richmond, VA) for his help on reviewing and editing this paper.

\section{References}

1. Third Report of the National Cholesterol Education Program (NCEP). Expert Panel on Detection, Evaluation, and Treatment of High Blood Cholesterol in Adults (Adult Treatment Panel III) final report. Circulation. 2002;106:3143-421.

2. Walldius G, Jungner I. Apolipoprotein B and apolipoprotein A-I: risk indicators of coronary heart disease and targets for lipidmodifying therapy. J Intern Med. 2004;255:188-205.

3. Walldius G, Jungner I. Rationale for using apolipoprotein B and apolipoprotein A-I as indicators of cardiac risk and as targets for lipid-lowering therapy. Eur Heart J. 2005;26:210-2.

4. Thompson A, Danesh J. Associations between apolipoprotein B, apolipoprotein $\mathrm{Al}$, the apolipoprotein $\mathrm{B} / \mathrm{Al}$ ratio and coronary heart disease: a literature-based meta-analysis of prospective studies. I Intern Med. 2006;259:481-92.

5. Sniderman AD, Furberg CD, Keech A, Roeters van Lennep JE, Frohlich J, Junger I, et al. Apoproteins versus lipids as indices of coronary risk and as targets for statin therapy. Lancet. 2003;361:777-80.

6. Williams K, Sniderman AD, Sattar N, D'Agostino R Jr, Wagenknecht LE, Haffner SM. Comparison of the associations of apolipoprotein $B$ and low-density lipoprotein cholesterol with other cardiovascular risk factors in the Insulin Resistance Atherosclerosis Study (IRAS). Circulation. 2003;108(19):2312-6.

7. Genest J Jr, McNamara JR, Ordovas JM, Jenner JL, Silberman SR, Anderson KM, et al. Lipoprotein cholesterol, apolipoprotein $\mathrm{A}-\mathrm{I}$ and $\mathrm{B}$ and lipoprotein (a) abnormalities in men with premature coronary artery disease. J Am Coll Cardiol. 1992;19(4):792-802.

8. Talmud PJ, Hawe E, Miller GJ, Humphries SE. Nonfasting apolipoprotein $\mathrm{B}$ and triglyceride levels as a useful predictor of coronary heart disease risk in middle-aged UK men. Arterioscler Thromb Vasc Biol. 2002;22:1918-23. 
9. Walldius G, Jungner I, Holme I, Aastveit AH, Kolar W, Steiner E. High apolipoprotein B, low apolipoprotein A-I, and improvement in the prediction of fatal myocardial infarction (AMORIS study): a prospective study. Lancet. 2001;358(9298):2026-33.

10. Lamarche B, Moorjani S, Lupien PJ, Cantin B, Bernard PM, Dagenais $G R$, et al. Apolipoprotein $A-I$ and $B$ levels and the risk of ischemic heart disease during a five-year follow-up of men in the Québec cardiovascular study. Circulation. 1996;94(3):273-8.

11. Sacks FM. The apolipoprotein story. Atheroscler Suppl. 2006;7:23-7.

12. Warnick GR, Nguyen T, Albers AA. Comparison of improved precipitation methods for quantification of high-density lipoprotein cholesterol. Clin Chem. 1985;31:217-22.

13. Walldius $G$, Jungner I. The apoB/apoA-I ratio: a strong, new risk factor for cardiovascular disease and a target for lipidlowering therapy--a review of the evidence. I Intern Med. 2006;259:493-519.

14. Rasouli M, Kiasari AM, Mokhberi V. The ratio of apoB/apoAl, apoB and lipoprotein (a) are the best predictors of stable coronary artery disease. Clin Chem Lab Med. 2006;44:1015-21.

15. Khadem-Ansari M H, Rasmi Y, Rahimi-Pour A, Jafarzadeh $M$. The association between serum apolipoprotein $\mathrm{A}-\mathrm{I}$ and apolipoprotein $B$ and the severity of angiographical coronary artery disease. Singapore Med J. 2009;50(6):610-3.

16. Bolibar I, Thompson SG, von Eckardstein A, Sandkamp M, Assmann G. Dose-response relationships of serum lipid measurements with the extent of coronary stenosis. Strong, independent, and comprehensive. ECAT Angina Pectoris Study Group. Arterioscler Thromb Vasc Biol. 1995; 15:1035-42.

17. Gardner CD, Fortmann SP, Krauss RM. Association of small lowdensity lipoprotein particles with the incidence of coronary artery disease in men and women. JAMA. 1996;276(11):875-81.
18. Stampfer MJ, Krauss RM, Ma J, Blanche PJ, Holl LG, Sacks FM, et al. A prospective study of triglyceride level, low-density lipoprotein particle diameter, and risk of myocardial infarction. JAMA. 1996;276(11):882-8.

19. Krauss RM. Is the size of low-density lipoprotein particles related to the risk of coronary heart disease? JAMA. 2002;287(6):712-3.

20. Williams PT, Superko HR, Haskell WL, Alderman EL, Blanche PJ, Holl LG, et al. Smallest LDL particles are most strongly related to coronary disease progression in men. Arterioscler Thromb Vasc Biol. 2003;23(2):314-21.

21. Mueller O, Chang E, Deng D, Franz T, Jing D, Kincaid R, et al. PROCAM Study: risk prediction for myocardial infarction using microfluidic high-density lipoprotein $(\mathrm{HDL})$ subfractionation is independent of HDL cholesterol. Clin Chem Lab Med. 2008;46(4):490-8.

Correspondence
Mohmed Ashmaig
Berkeley Heart Lab. Inc. - 960 Atlantic AVE,
Alameda, CA 94501, USA
E-mail: moh20_2000@yahoo.com
Authors contributions
Conception and design: MA, KA, AA, SS, MA
Analysis and interpretation: MA
Data collection: MA, KA, AA, SS, MA
Writing the article: MA
Critical revision of the article: MA, KA, SS, RGW, MA
Final approval of the article*: MA, KA, AA, SS, RGW, MA
Statistical analysis: MA
Overall responsibility: MA
Obtained funding: N/A
* All authors have read and approved the final version of the article submitted
to J Vasc Bras.

